\title{
THE IMPACT OF DIGITAL TECHNOLOGIES ON THE LEGAL REGIME FOR THE PROTECTION OF PERSONAL DATA IN BANKING ${ }^{1}$
}

\author{
Olesya P. Kazachenok \\ Volgograd State University, Volgograd, Russian Federation
}

Introduction: currently, the information technologies are at a very high level, so there may be the situations of data leakage, thereby increasing the risk of obtaining information by third parties, moreover, the electronic format of information threatens personal information security, so it seems necessary to adapt the domestic legislation to the current processes of "digitalization" and create a system of comprehensive protection of personal data in banking, necessary in the transition to Industry 4.0. The purpose of the work is to study the impact of digital technologies on the legal regime for the protection of personal data in banking, to develop proposals for improving the legislation in this area, to identify the risks of unauthorized access to personal data in the context of digitalization. Methods: the methodological framework for the study consists of: the methods of scientific analysis, logical analysis and the dialectical method. Results: the result of the research is the development of proposals for improving the regulatory framework in the field of personal data protection in banking in the context of the active development of digital technologies. Conclusions: the conclusion is made about the advantages and disadvantages of using blockchain in the banking sector, the need to develop a regulatory framework that regulates the activities of entities using such technologies. The author draws attention to the existing payment systems that have proven their efficiency in the banking sector. In addition, in order to prevent cases of leaking personal information of the bank customers, it seems appropriate to eliminate the existing legal uncertainty and unify the rules governing the legal regime for the protection of personal data in banking, in particular, the author supports the idea of concluding an agreement on electronic information interaction between the Central Bank and the Ministry of Internal Affairs of Russia, so that the law enforcement agencies can quickly respond to fraudulent actions and prevent them.

Key words: personal data, legal regime, blockchain technologies, digitalization, digital technologies, banking, banking secrecy.

Citation. Kazachenok O.P. The Impact of Digital Technologies on the Legal Regime for the Protection of Personal Data in Banking. Legal Concept = Pravovaya paradigma, 2021, vol. 20, no. 1, pp. 99-104. (in Russian). DOI: https://doi.org/10.15688/lc.jvolsu.2021.1.15

УДК 341.22:339.7.012

Дата поступления статьи: 08.01.2021

ББК 67.911.221.3

Дата принятия статьи: 09.02.2021

\section{ВОЗДЕЙСТВИЕ ЦИФРОВЫХ ТЕХНОЛОГИЙ НА ПРАВОВОЙ РЕЖИМ ЗАЩИТЫ ПЕРСОНАЛЬНЫХ ДАННЫХ В БАНКОВСКОЙ ДЕЯТЕЛЬНОСТИ ${ }^{1}$}

\author{
Олеся Павловна Казаченок \\ Волгоградский государственный университет, г. Волгоград, Российская Федерация
}

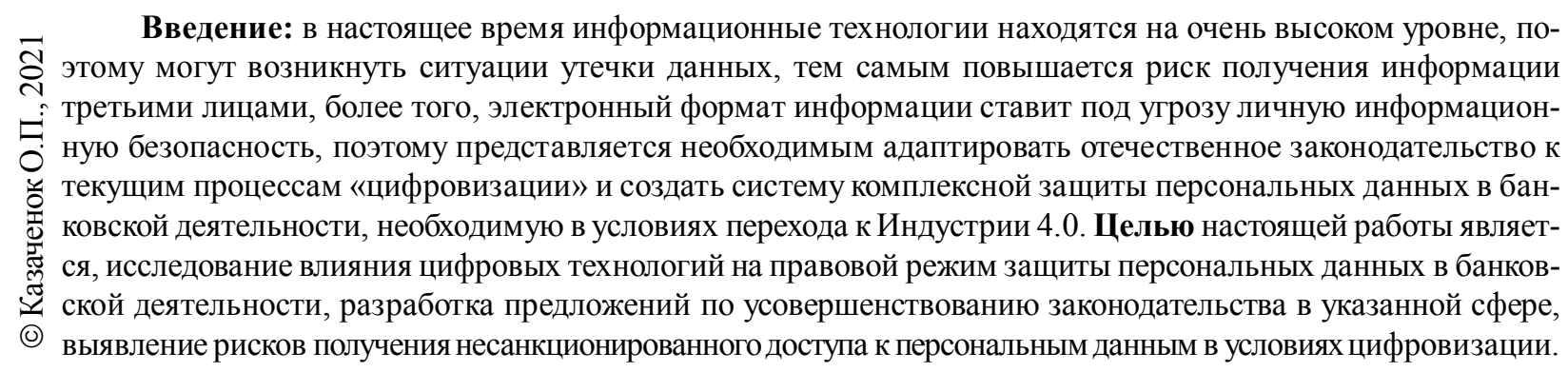


Методологическую основу работы составляют: метод научного анализа, диалектический метод, метод логического анализа. Результатом проведенного исследования является разработка предложений по усовершенствованию нормативно-правовой базы в сфере защиты персональных данных в банковской деятельности в условиях активного развития цифровых технологий. Выводы: делается вывод о преимуществах и недостатках использования блокчейн в банковской сфере, необходимости разработки нормативно-правовой базы, регулирующей деятельность субъектов с применением таких технологий. Автор обращает внимание на существующие платежные системы, доказавшие свою эффективность в банковском секторе. Кроме того, в целях предотвращения случаев утечки сведений о персональных данных клиентов банков представляется целесообразным устранить существующую правовую неопределенность и унифицировать нормы, регулирующие правовой режим защиты персональных данных в банковской деятельности, в частности, автор поддерживает идею о заключении договора об электронном информационном взаимодействии между ЦБ и МВД России, благодаря чему правоохранительные органы смогут оперативно реагировать на мошеннические действия и пресекать их.

Ключевые слова: персональные данные, правовой режим, блокчейн-технологии, цифровизация, цифровые технологии, банковская деятельность, банковская тайна.

Цитирование. Казаченок О. П. Воздействие цифровых технологий на правовой режим защиты персональных данных в банковской деятельности // Legal Concept = Правовая парадигма. - 2021. - Т. 20, № 1. - C. 99 104. - DOI: https://doi.org/10.15688/lc.jvolsu.2021.1.15

\section{Введение}

Банковская сфера - сегмент экономики, который подвергается активной трансформации под воздействием распространения новых технологий. В настоящее время, на этапе становления цифровой экономики, ведущим направлением развития России является цифровизация экономической и правовой систем [4, с. 184].

Становление цифровой экономики требует изменений отечественного законодательства в соответствии с новыми правоотношениями [1, с. 7]. Из вышесказанного следует, что исследование проблем правового регулирования защиты персональных данных в настоящее время является особенно актуальным.

Следовательно, целесообразно провести исследование правового режима защиты персональных данных в банковской деятельности в Российской Федерации и определить основные направления развития российского законодательства в указанной сфере с учетом активного воздействия цифровых технологий $[6$, с. 10].

Проблемы нормативно-правового характера обнаруживаются, в частности, при регулировании правового режима защиты банковской тайны, если информация, составляющая ее, была получена государственными должностными лицами (или наоборот). В этом случае каждый субъект будет иметь свой собственный правовой режим защиты информации.
Кроме того, при идентификации личности клиента остро стоят проблемы нормативно-правового характера и др.

\section{Блокчейн-технологии и перспективы их использования в банковской сфере}

В контексте цифровизации следует упомянуть блокчейн - распределенная база данных, в основе которой - децентрализованная пиринговая одноранговая сеть (Р2Р), использующая механизм достижения соглашений, криптографию и блоки обратной ссылки для совершения сделок [5, с. 147].

Данная технология основана на полной анонимности. В настоящее время блокчейн часто используется в противозаконных целях. Особенно популярным является даркнет, где применяются технологии блокчейн. В даркнете анонимно приобретают оружие, наркотики и другие запрещенные предметы. Необходимо отметить, что участников таких операций очень сложно выявить. Как видим, с помощью блокчейн-технологий происходит легализация преступных доходов, а также данную технологию могут использовать в террористических целях.

В целях обеспечения комплексной защиты персональных данных для банков использование блокчейн, безусловно, имеет отдельные преимущества, но вместе с тем вследствие указанных выше обстоятельств на прак- 
О.П. Казаченок. Воздействие цифровых технологий на правовой режим защиты персональных данных

тике могут возникнуть определенные проблемы - правовые риски при внедрении блокчейн в банковский сектор экономики. Для того чтобы наиболее эффективно применять технологии блокчейн, необходимо разработать технологию, которая не противоречила бы законодательству и позволяла бы оптимально использовать преимущества таких технологий.

Как считает исследователь В.М. Камалян, необходимо в процесс идентификации включить блокчейн-технологии. Иными словами, посредством разработки и утверждения на законодательном уровне новой системы идентификации личности на основе блокчейнтехнологии персональные данные клиента являются абсолютно защищенными. Благодаря таким технологиям банк сможет оперативно и в полном объеме получать необходимую информацию, а также полностью обеспечить комплексную защиту персональных данных клиентов, исключив возможную утечку данных благодаря созданной зашифрованный системе [7, с. 35].

Не все исследователи солидарны с указанной точкой зрения. В отличие от приведенного выше мнения, Л.Г. Ефимова считает, что, несмотря на очевидные преимущества использования блокчейн-технологий в банковской сфере, среди которых наличие выгоды при переводе средств в результате значительного снижения издержек, следует учитывать и риски, возникающие на практике:

1) блокчейн может обеспечить не полную, а частичную анонимность пользователей, а значит, создает препятствия банкам в борьбе с легализацией доходов, полученных преступным путем и финансированием терроризма;

2) необратимость и неизменность операций в блокчейн. Иными словами, публичный блокчейн не является гарантией окончательности проведенных расчетов;

3) при использовании блокчейн-технологий банк теряет свою ведущую функцию финансового посредника [13, с. 179].

Л.Г. Ефимова указывает на наличие правовых рисков при использовании блокчейн и судебной защите в связи с отсутствием нормативно-правовой базы, регулирующей отношения в данной сфере, так как на блокчейн традиционные механизмы исполнения судебных решений не распространяются.
Несмотря на указанные недостатки в использовании блокчейн банками, исследователь допускает такие технологии в целях осуществления отдельных расчетных операций (например, расчеты посредством аккредитива), организации кредитования, оформления и исполнения договора залога; выпуска и размещения ценных бумаг (облигаций и депозитных сертификатов) [13, с. 181].

Следует заметить, что в настоящее время в мире существуют и работают некоторые модели, использующие блокчейнтехнологии.

Так, в качестве положительного примера в использовании блокчейн в банковской сфере можно обратить внимание на всемирно известную криптовалютную платформу Ripple, разработанную в 2012 г., - платежную систему перевода денежных средств с небольшой комиссией, которую используют крупные финансовые организации, в том числе и банки.

Модель Civic в 2017 г. удостоилась премии на специализированной конференции, доказав свою эффективность в проверке подлинности личности [14, p. 247]. В данной модели участниками могут выступать банки, иные финансовые организации. Преимущество указанной модели состоит в том, что компания не хранит информацию о пользователях, а для защиты сведений используются блокчейн-технологии. Данные, которыми обмениваются пользователи, не попадают в руки иных лиц. Такая система очень удобна в применении и позволяет защищать персональные данные клиентов сервиса [8].

Таким образом, использование технологий блокчейн в настоящее время является очень перспективным направлением в сфере защиты персональных данных. Для их активного применения банкам следует разработать отдельные законодательные акты либо внести поправки в существующее законодательство о банковской тайне, которые позволят оптимально использовать современные цифровые технологии и в то же время не допустить утечки персональных данных и сохранить банковскую тайну.

Следовательно, положительный эффект от использования цифровых технологий в банковской сфере должен быть обеспечен госу- 
дарственной поддержкой в виде разработки концепции правового регулирования использования современных блокчейн-технологий.

Следует заметить, что на продукты, созданные на основе технологии блокчейн, в настоящее время распространяются нормы Федерального закона от 27.07.2006 № 149-Ф3 «Об информации, информационных технологиях и о защите информации» о соблюдении конфиденциальности информации, доступ к которой ограничен федеральным законодательством.

Тем не менее отсутствует нормативно-правовая база, регулирующая деятельность субъектов с применением блокчейнтехнологий.

\section{Противодействие росту количества случаев утечки сведений \\ о персональных данных, вызванное развитием цифровых технологий}

Как указано выше, в настоящее время наблюдается рост количества случаев утечки сведений о счетах граждан и других персональных данных.

Доступ к информации, составляющей банковскую тайну, предоставляется только сотрудникам соответствующих направлений бизнеса, службам безопасности, а также членам совета директоров и владельцам бизнеса.

Помимо указанных в ст. 857 Гражданского кодекса Российской Федерации [2] лиц, ряд органов власти Российской Федерации может иметь доступ к персональным данным, содержащим банковскую тайну. Информация, составляющая банковскую тайну, также может быть предоставлена клиентам или их представителям.

Сотрудники банков и иные лица за разглашение банковской тайны несут ответственность согласно ст. 183 УК РФ [11]. В соответствии с указанной нормой среди наказаний за данное преступление - крупные штрафы и лишение свободы.

Государственным органам и их должностным лицам может предоставляться такая информация только в случаях и в порядке, предусмотренных законом.

Согласно п. 1 ст. 86 НК РФ [9] налоговые органы вправе без запроса получать информацию от банков на основании прямого указания закона. Часто на практике возникают споры, в которых инспекция просит привлечь к ответственности банк за несвоевременное направление информации в адрес налогового органа. Суд может привлечь банк к ответственности в случае наличия доказательств ненадлежащего исполнения банком своих обязанностей по направлению сведений [10].

В 2017 г. активно обсуждался вопрос предоставлении доступа к персональным данным, содержащим банковскую тайну, правоохранительным органам.

Так, глава Центробанка Э. Набиуллина отметила, что на законодательном уровне должно быть закреплено предоставление подобной информации правоохранительным органам - шаг к эффективной борьбе с недобросовестными банкирами [3]. Данная мера, по мнению главы Центробанка, особенно актуальна в связи с частыми случаями мошенничества в банках, растраты активов. В настоящее время Центральный банк ограничен (с точки зрения формальных критериев) в случаях, в которых возможно вмешательство надзорных органов, что приводит к негативным последствиям: затруднению установления состава преступления и определению подозреваемых.

Главой МВД России В. Колокольцевым было предложено заключить договор об информационном взаимодействии между ЦБ и МВД в связи с необходимостью ускорения процесса получения необходимой информации с целью оперативного предотвращения изъятия денег из банков. Указанная мера направлена на осуществление контроля в целях предотвращения преступности и борьбы с коррупцией.

Так, примером может служить ситуация с выводом денег из Промсвязьбанка и ФК «Открытие». В период с 2016 по 2017 г. были обнаружены нарушения: вывод денежных средств (104 млрд руб.), но уголовное дело было возбуждено спустя 2 года.

В 2020 г. данная проблема снова стала объектом дискуссий. В настоящее время ЦБ РФ не считает необходимым расширять права правоохранительных органов и получать доступ к банковской тайне [12].

Полагаем, сложившаяся ситуация создает проблемы, обусловленные неоднозначностью толкования некоторых положений законов. 
О.П. Казаченок. Воздействие цифровых технологий на правовой режим защиты персональных данных

\section{Выводы}

Таким образом, активное развитие цифровых технологий влияет на банковский сектор. Данные процессы происходят в условиях развития цифровой экономики в Российской Федерации, основой которой является информация. Соответственно, необходимо оперативно отслеживать данные проблемные процессы и нейтрализовать возникающие риски.

Стремительное развитие информационных технологий ведет к необходимости дополнения и уточнения списка органов, имеющих доступ к банковской тайне. С этой точки зрения заключение договора об электронном информационном взаимодействии между ЦБ и МВД России позволит правоохранительным органам оперативно реагировать на мошеннические действия и пресекать их.

По нашему мнению, в целях предотвращения случаев утечки сведений о персональных данных клиентов банков представляется целесообразным устранить существующую правовую неопределенность и унифицировать нормы, регулирующие правовой режим защиты персональных данных в банковской деятельности с учетом трансформации данных отношений под воздействием цифровой экономики.

\section{ПРИМЕЧАНИЕ}

${ }^{1}$ Исследование выполнено при финансовой поддержке Российского научного фонда (проект № 20-18-00314).

The study was carried out with the financial support of the Russian Science Foundation (project No. 20-18-00314).

\section{СПИСОК ЛИТЕРАТУРЫ}

1. Городов, О. А. Основные направления совершенствования правового регулирования в сфере цифровой экономики в России / О. А. Городов, М. А. Егорова // Право и цифровая экономика. 2018. - № 1 (01). - С. 6-12.

2. Гражданский кодекс Российской Федерации (часть вторая) от 26.01.1996 № 14-ФЗ (ред. от 27.12 .2019 , с изм. от 28.04.2020) // Собрание законодательства РФ. - 1996. - 29 окт. (№ 5). - Ст. 410.

3. Информационное агентство ТАСС. - Электрон. тектстовые дан. - Режим доступа: https:// tass.ru/ekonomika/4008416. - Загл. с экрана.
4. Иншакова, А. О. Вековой поиск модели хозяйственного развития России: экономико-правовое развитие конкурентоспособного государства / А. О. Иншакова // Legal Concept = Правовая парадигма. - 2019. - Т. 18, № 4. - C. 184-187. -DOI: https://doi.org/10.15688/lc.jvolsu.2019.4.26.

5. Казаченок, О. П. Взаимное (Р2P) кредитование как современный инструмент альтернативного финансирования / О. П. Казаченок // Вестник университета им. О.Е. Кутафина (МГЮА). - 2018. № 10 (50). - C. 147-155.

6. Казаченок, О. П. Криптовалюта как объект гражданских прав в правоприменительной деятельности / О. П. Казаченок // Вестник арбитражной практики. - 2019. - № 3. - С. 10-17.

7. Камалян, В. М. Правовые риски использования цифровых технологий в банковской деятельности / В. М. Камалян // Актуальные проблемы российского права. - 2019. - № 6 (103). - С. 32-39.

8. Матыцин, Д. Е. Цифровые технологии реализации гражданско-правовых правовых сделок: договор репо на инвестиционные активы рынка ценных бумаг / Д. Е. Матыцин // Право и практика. 2020. - №2.- С. 136-140.

9. Налоговый кодекс Российской Федерации (часть первая) от 31.07.1998 № 146-ФЗ (ред. от 23.11.2020) // Российская газета. - 1998. - № 148-149.

10. Постановление ФАС Западно-Сибирского округа от 27 сентября 2013 г. № A75-9874/2012. Доступ из справ.-правовой системы «КонсультантПлюс».

11. Уголовный кодекс Российской Федерации от 13.06.1996 № 63-Ф3 (ред. от 30.12.2020) // Собрание законодательства Российской Федерации. 1996. - № 25. - Ст. 2954.

12. ЦБ РФ не считает нужным расширять доступ МВД к банковской тайне // Российская газета. Электрон. текстовые дан. - Режим доступа: https:// rg.ru/2020/04/29/cb-rf-ne-schitaet-nuzhnym-rasshiriatdostup-mvd-k-bankovskoj-tajne.html (дата обращения: 22.12.2020). - Загл. с экрана.

13. Цифровое право в банковской деятельности: сравнительно-правовой аспект : монография / отв. ред. Л. Г. Ефимова. - М. : Проспект, 2021. -416 с.

14. Khramtsova, N. Prospects for the Development of Legislation in the Field of Bank Secrecy as an Information Security Institution at the Stage of the Digital Economy / N. Khramtsova // Advances in Social Science, Education and Humanities Research. - 2019. - Vol. 392. - P. 247-250.

\section{REFERENCES}

1. Gorodov, O.A. Osnovnye napravlenija sovershenstvovanija pravovogo regulirovanija v sfere 
cifrovoj jekonomiki v Rossii [The Main Directions of Improving Legal Regulation in the Digital Economy in Russia]. Pravo i cifrovaja jekonomika [Law and the Digital Economy], 2018, no. 1 (01), pp. 6-12.

2. Grazhdanskij kodeks Rossijskoj Federacii (chast vtoraja) ot 26.01.1996 № 14-FZ (red. ot 27.12.2019, $\mathrm{s}$ izm. of 28.04.2020) [Civil Code of the Russian Federation (Part Two) Dated 26.01.1996 No. 14-FZ]. Sobranie zakonodatelstva Rossiyskoy Federatsii [Collection of Legislation of the Russian Federation], 1996, Jan 29 (no. 5), art. 410.

3. Informacionnoe agentstvo TASS. URL: https://tass.ru/ekonomika/4008416.

4. Inshakova A.O. Vekovoj poisk modeli hozjajstvennogo razvitija Rossii: jekonomiko-pravovoe razvitie konkurentosposobnogo gosudarstva [The Age-Old Search for a Model of Economic Development in Russia: Economic and Legal Development of a Competitive State]. Legal Concept, 2019, vol. 18, no. 4, pp. 184-187.

5. Kazachenok O.P. Vzaimnoe (R2R) kreditovanie kak sovremennyj instrument alternativnogo finansirovanija [Mutual (P2P) Lending as a Modern Instrument of Alternative Financing]. Vestnik universiteta im. O.E. Kutafina (MGJuA) [University Bulletin O.E. Kutafina (Moscow State Law Academy)], 2018, no. 10 (50), pp. 147-155.

6. Kazachenok O.P. Kriptovaljuta kak obekt grazhdanskih prav v pravoprimenitelnoj dejatelnosti [Cryptocurrency as an Object of Civil Rights in Law Enforcement]. Vestnik arbitrazhnoj praktiki [Arbitration Practice Bulletin], 2019, no. 3, pp. 10-17.

7. Kamaljan V.M. Pravovye riski ispolzovanija cifrovyh tehnologij v bankovskoj dejatelnosti [Legal Risks of Using Digital Technologies in Banking]. Aktualnye problemy rossijskogo prava [Actual Problems of Russian Law], 2019, no. 6 (103), pp. 32-39.
8. Matytsin D.E. Tsifrovye tekhnologii realizatsii grazhdansko-pravovykh pravovykh sdelok: dogovor repo na investitsionnye aktivy rynka tsennykh bumag [Digital Technologies for the Implementation of Civil Law Legal Transactions: Repo Agreement for Investment Assets of the Securities Market]. Pravo $i$ praktika [Law and Politics], 2020, no. 2, pp. 136-140.

9. Nalogovyj kodeks Rossijskoj Federacii (chast pervaja) ot 31.07.1998 g. № 146-FZ (red. ot 23.11.2020) [Tax Code of the Russian Federation (Part One) of July 31, 1998 No. 146-FZ]. Rossijskaja gazeta [Russian newspaper], 1998, no. 148-149.

10. Postanovlenie FAS Zapadno-Sibirskogo okruga ot 27 sentjabrja 2013 g. № A75-9874/2012 [FAS Resolution of the West Siberian District of September 27, 2013 No. A75-9874 / 2012]. Access from Reference Legal Sistem “KonsultantPlyus”.

11. Ugolovnyj kodeks Rossijskoj Federacii ot 13.06.1996 № 63-FZ (red. ot 30.12.2020) [The Criminal Code of the Russian Federation of 13.06.1996 No. 63FZ]. Sobranie zakonodatelstva Rossiyskoy Federatsii [Collection of legislation of the Russian Federation], 1996, no. 25, art. 2954.

12. CB RF ne schitaet nuzhnym rasshirjat dostup MVD k bankovskoj tajne. Rossijskaja gazeta. URL: https://rg.ru/2020/04/29/cb-rf-ne-schitaet-nuzhnymrasshiriat-dostup-mvd-k-bankovskoj-tajne.html (accessed 22 December 2020).

13. Cifrovoe pravo v bankovskoj dejatelnosti: sravnitelno-pravovoj aspekt: monografija [Digital Law in Banking: Comparative Legal Aspect: Monograph]. Moscow, Prospekt Publ., 2021. 416 p.

14. Khramtsova, N. Prospects for the Development of Legislation in the Field of Bank Secrecy as an Information Security Institution at the Stage of the Digital Economy. Advances in Social Science, Education and Humanities Research, 2019, vol. 392, pp. 247-250.

\section{Information About the Author}

Olesya P. Kazachenok, Candidate of Sciences (Jurisprudence), Associate Professor, Department of Civil and Private International Law (Base Department of the Southern Scientific Centre of the Russian Academy of Sciences), Volgograd State University, Prosp. Universitetsky, 100, 400062 Volgograd, Russian Federation, gimchp@volsu.ru, https://orcid.org/0000-0001-9675-367X

\section{Информация об авторе}

Олеся Павловна Казаченок, кандидат юридических наук, доцент кафедры гражданского и международного частного права (базовая кафедра ЮНЦ РАН), Волгоградский государственный университет, просп. Университетский, 100, 400062 г. Волгоград, Российская Федерация, gimchp@volsu.ru, https://orcid.org/0000-0001-9675-367X 